\title{
Regioisomeric Family of Novel Fluorescent Substrates for SHIP2
}

\author{
Gaye White, ${ }^{\dagger, \|}$ Christopher Prior, ${ }^{\ddagger}, \|$ Stephen J. Mills, ${ }^{\S}, \|$ Kendall Baker, ${ }^{\dagger}$ Hayley Whitfield, ${ }^{\dagger}$

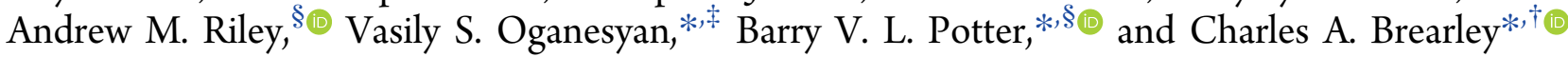 \\ ${ }^{\dagger}$ School of Biological Sciences, UEA, Norwich Research Park, Norwich NR4 7TJ, U.K. \\ ${ }^{\ddagger}$ School of Chemistry, UEA, Norwich Research Park, Norwich NR47TJ, U.K. \\ ${ }^{\S}$ Medicinal Chemistry \& Drug Discovery, Department of Pharmacology, University of Oxford, Mansfield Road, Oxford OX1 3QT, \\ U.K.
}

\section{Supporting Information}

ABSTRACT: SHIP2 (SH2-domain containing inositol 5phosphatase type 2) is a canonical 5-phosphatase, which, through its catalytic action on PtdInsP $\mathrm{P}_{3}$, regulates the PI3K/ Akt pathway and metabolic action of insulin. It is a drug target, but there is limited evidence of inhibition of SHIP2 by small molecules in the literature. With the goal to investigate inhibition, we report a homologous family of synthetic, chromophoric benzene phosphate substrates of SHIP2 that display the headgroup regiochemical hallmarks of the physiological inositide substrates that have proved difficult to crystallize with 5-phosphatases. Using time-dependent density functional theory (TD-DFT), we explore the intrinsic fluorescence of these novel substrates and show how

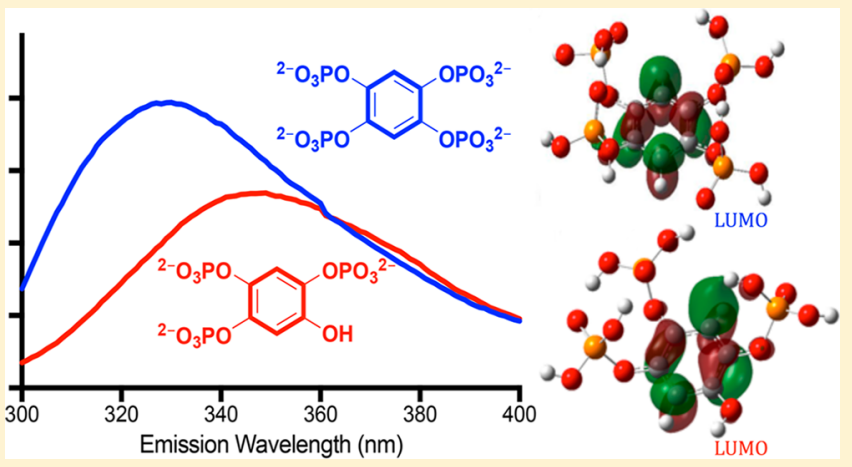
fluorescence can be used to assay enzyme activity. The TD-DFT approach promises to inform rational design of enhanced active site probes for the broadest family of inositide-binding/metabolizing proteins, while maintaining the regiochemical properties of bona fide inositide substrates.

KEYWORDS: Inositol phosphate, 5-phosphatase, SHIP2, TD-DFT, fluorescence, HPLC, ligand

Tn n eukaryotic cells, many signaling pathways are regulated by levels of inositol phosphates (inositides), phosphatidylinositol phosphates (phosphoinositides), and the proteins that are their cognate binding partners. The balance of these is controlled by families of kinases and phosphatases that phosphorylate and dephosphorylate these molecules at specific positions, designated locants, of the inositol ring. ${ }^{1} \mathrm{SH} 2$-domain containing inositol 5-phosphatase type 2 (SHIP2) belongs to a family of phosphatases that hydrolyze the 5-phosphate of inositides and phosphoinositides. The substrates are known to include inositol pentakisphosphates $\left(\mathrm{InsP}_{5}\right)$, tetrakisphosphates $\left(\mathrm{InsP}_{4}\right)$, trisphosphates ( $\left.\operatorname{Ins}_{3}\right)$, phosphatidylinositol 3,4,5-trisphosphate (PtdInsP $\mathrm{P}_{3}$ ), and phosphatidylinositol 4,5bisphosphate $\left(\mathrm{PtdInsP}_{2}\right)^{2}$

An understanding of how these enzymes function is important to pathologies such as diabetes and cancer. ${ }^{2}$ SHIP2 reduces levels of PtdIns $\mathrm{P}_{3}$, while increasing levels of $\operatorname{PtdIns}(3,4) \mathrm{P}_{2}$. Consequently, this enzyme regulates the PI3K/ Akt pathway that is linked to cell proliferation and the metabolic action of insulin. ${ }^{3,4}$ SHIP2 is expressed in many cell types and has additionally been linked to regulation of diverse cellular processes such as calcium signaling, cytoskeletal remodeling, protein trafficking, and phagocytosis. ${ }^{2,5}$ While a mechanistic explanation of inhibition of PI3-kinases has underpinned therapeutic interventions in cancer, ${ }^{6,7}$ therapeutic inhibition of 5-phosphatases lacks similar foundation.

Previous research for inhibitors of SHIP2 has typically assayed activity using phosphate release with $\mathrm{D}$-myo-inositol1,3,4,5-tetrakisphosphate $\left(\operatorname{Ins}(1,3,4,5) \mathrm{P}_{4}\right)$ or D-myo-phosphatidylinositol-3,4,5-trisphosphate $\left(\operatorname{PtdIns}(3,4,5) \mathrm{P}_{3}\right){ }^{8}$ Thus, Suwa et al. identified AS1949490 as a novel, small molecule inhibitor of SHIP2. In the absence of structural data or evidence of catalytic modification of the inhibitor, the exact mode of inhibition is not clear, though from an enzymological perspective the nature of inhibition is competitive with respect to inositide substrate. It is possible that within the chemical landscape of inhibition, competitive substrate analog inhibitors will be found. However, further mechanistic analysis would require identification of the products of such reactions, something limited for bona fide substrates by lack of a suitable chromophore in these molecules. Alternatively, radiolabeled substrates could be used, but this would demand complex

Special Issue: Women in Medicinal Chemistry

Received: August 8, 2019

Accepted: October 18, 2019

Published: October 18, 2019 
synthetic work and HPLC resolution of substrates and products.

With a view to finding alternative substrates of 5phosphatases that have analytically useful chromophoric properties, we investigated the benzene polyphosphate compounds shown in Figure 1. Originally, the benzene

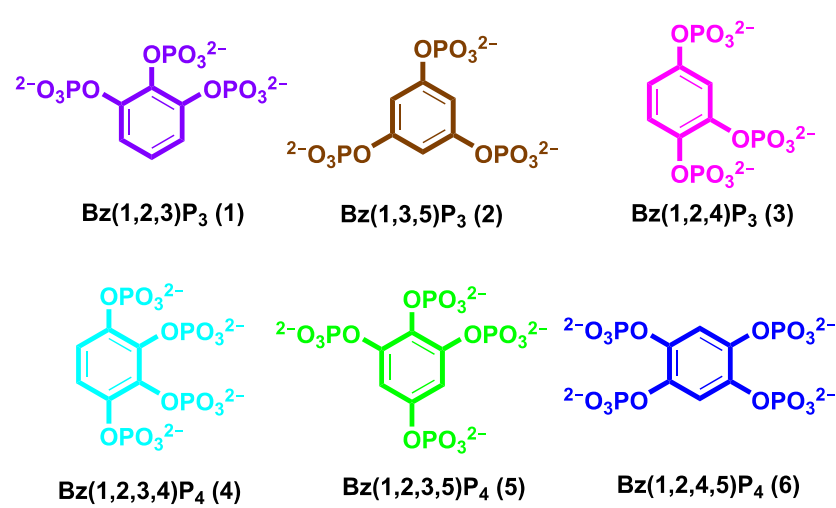

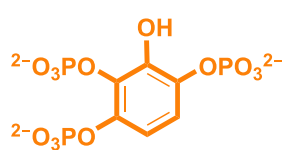

3-OH-Bz(1,2,4) $\mathrm{P}_{3}(7)$

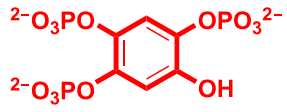

$5-\mathrm{OH}-\mathrm{Bz}(1,2,4) \mathrm{P}_{3}(8)$
Figure 1. Structures of benzene phosphates used in this study.

phosphate compounds $\mathbf{1}$ to $\mathbf{6}$ were designed as substrate analogs to substitute as ligands to inositol phosphate binding proteins/enzymes, enabling crystallographic resolution of protein-ligand complexes and insight into enzyme inhibition. ${ }^{9,10}$ While simple benzene phosphates appear not to be substrates of 5 -phosphatases, ${ }^{9-11}$ compound $7,3-\mathrm{OH}-\mathrm{Bz}-$ $(1,2,4) \mathrm{P}_{3}$, was synthesized and has been shown by assay of release of phosphate to be a substrate for type I myo-inositol 1,4,5-triphosphate-5-phosphatase (INPP5A). ${ }^{11}$ Benzene phosphate analogues were also used to uncover mechanistic information in cocrystallization studies with INPP5B. ${ }^{12}$

We now show that the chromophoric properties of benzene phosphates vary depending on the regiochemistry of substituents around the benzene ring and that several members of this family have an unanticipated, useful, intrinsic fluorescence. Alongside conventional spectroscopic measurements, we use time-dependent density functional theory (TDDFT) to examine how the regiochemistry modifies the spectroscopic properties. Compound $6, \mathrm{Bz}(1,2,4,5) \mathrm{P}_{4}$, proved to be intensely fluorescent, a property potentially explainable by TD-DFT. It is a tantalizing observation that the four phosphate groups of this compound are stereochemically homotopic, remaining indistinguishable even in the chiral environment of the enzyme active site. Since 5-phosphatases yield only a single product from $\operatorname{Ins}(1,3,4,5) \mathrm{P}_{4}$, should benzene phosphates be substrates, we expect a single, identifiable product $85-\mathrm{OH}-\mathrm{Bz}(1,2,4) \mathrm{P}_{3}$ of the dephosphorylation of compound $6 \mathrm{Bz}(1,2,4,5) \mathrm{P}_{4}$. Compound 8 5-OH-Bz $(1,2,4) \mathrm{P}_{3}$ was, however, not synthesized, so in the absence of reference material, we sought to use TD-DFT to predict its fluorescence with the expectation of being able to use this prediction to identify whether compound $6 \mathrm{Bz}(1,2,4,5) \mathrm{P}_{4}$ could be a substrate of SHIP2. We therefore investigated the possibility that benzene phosphates themselves are substrates for dephosphorylation by SHIP2 and the chromophoric properties of this class of molecule might allow construction of assays complementary to those that employ the measurement of released inorganic phosphate.

Previously, benzene phosphates have been shown to be inhibitors of INPP5A, ${ }^{7}$ INPP5B, ${ }^{12}$ and SHIP2, ${ }^{8}$ with compound $6 \mathrm{Bz}(1,2,4,5) \mathrm{P}_{4}$ yielding $\mathrm{IC}_{50}$ values in single figures and tens of micromolar range against $\operatorname{Ins}(1,4,5) \mathrm{P}_{3}$ and Ins $(1,3,4,5) \mathrm{P}_{4}$ substrates, tested at 1 and $100 \mu \mathrm{M}$ concentrations, respectively. We also recently described the use of a fluorescent conjugate of $\operatorname{Ins}(1,3,4,5,6) \mathrm{P}_{5}\left(2\right.$-FAM-InsP $\mathrm{P}_{5}$, Figure $2)$ as an active site probe of inositol pentakisphosphate 2-

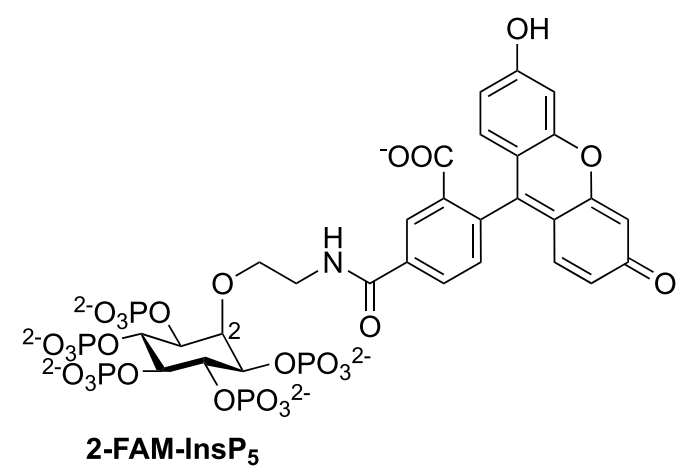

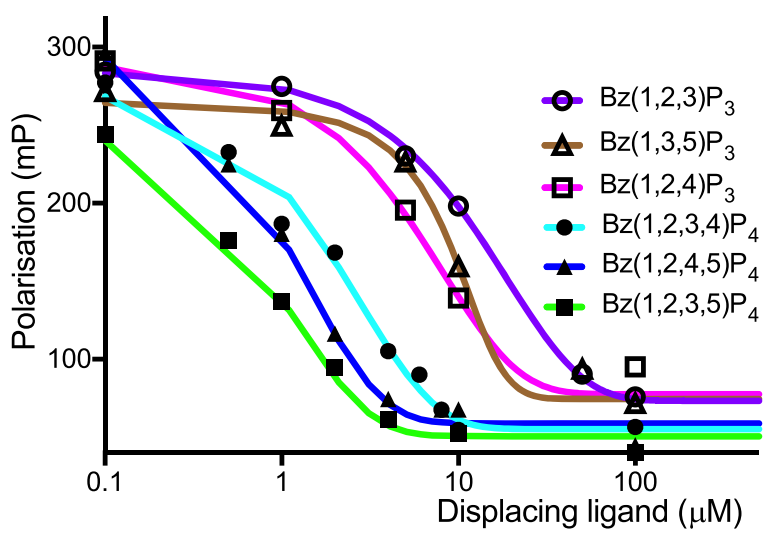

Figure 2. Displacement of 2-FAM-InsP $\mathrm{P}_{5}$ from SHIP2 by benzene phosphates. The experiments used $2 \mathrm{nM} 2$-FAM-InsP $P_{5}$ and $1 \mu \mathrm{M}$ SHIP2. Results shown as mean of triplicate experiments (results with standard deviations given in Table 1).

kinase $^{13}$ and as an intracellular probe. ${ }^{14}$ Here, combining the use of two classes of ligand, we show that displacement of 2FAM-InsP ${ }_{5}$ affords an assay of benzene phosphate binding to SHIP2 (Figure 2 and Table 1).

All six benzene phosphate derivatives chosen displaced $2 \mathrm{nM}$ 2-FAM-InsP ${ }_{5}$ from SHIP2 with $\mathrm{IC}_{50}$ values in the low micromolar range, the benzene tetrakisphosphates being more effective than benzene trisphosphates, with $\mathrm{IC}_{50}$ values approximately 1 order of magnitude smaller than the trisphosphates.

Most commonly, 5-phosphatase activity is assayed as the release of inorganic phosphate from Ins $(1,3,4,5) \mathrm{P}_{4}$ or PtdIns$(3,4,5) \mathrm{P}_{3}$. We assayed the ability of SHIP2 to release phosphate from inositol phosphates and also benzene phosphates. We tested whether, by virtue of the lower $\mathrm{p} K_{\mathrm{a}}$ of the hydroxyl of a theoretical dephosphorylated benzene phosphate (leaving group), ${ }^{15,16}$ benzene phosphates might be 
Table 1. Comparison of Published IC $_{50}$ Values for Inhibition of 5-Phosphatases by Benzene Phosphates to Experimentally Determined $\mathrm{IC}_{50}$ Values Found for Displacement of 2-FAM-InsP $\mathrm{P}_{5}$ from SHIP2

\begin{tabular}{|c|c|c|c|c|}
\hline compound & $\mathrm{IC}_{50}(\mu \mathrm{M}) \underset{\substack{2 \\
\text { study }}}{2-\mathrm{FAM}-\mathrm{InsP}_{5}}$ SHIP2, this & $\operatorname{IC}_{50}(\mu \mathrm{M}) \operatorname{Ins}(1,3,4,5) \mathrm{P}_{4}$ & $\mathrm{IC}_{50}(\mu \mathrm{M}) \operatorname{Ins}(1,4,5) \mathrm{P}_{3}$ & $\mathrm{IC}_{50}(\mu \mathrm{M}) \operatorname{Ins}(1,4,5) \mathrm{P}_{3}$ \\
\hline $\mathrm{Bz}(1,2,3) \mathrm{P}_{3}$ & $14.23 \pm 0.1$ & $>1000$ & $86 \pm 28$ & $33.5 \pm 6.8$ \\
\hline $\mathrm{Bz}(1,3,5) \mathrm{P}_{3}$ & $11.25 \pm 2.9$ & & $16 \pm 9$ & \\
\hline $\mathrm{Bz}(1,2,4) \mathrm{P}_{3}$ & $7.02 \pm 0.05$ & & $14 \pm 9$ & \\
\hline $\mathrm{Bz}(1,2,3,4) \mathrm{P}_{4}$ & $2.78 \pm 0.59$ & & $98 \pm 16$ & \\
\hline $\mathrm{Bz}(1,2,3,5) \mathrm{P}_{4}$ & $1.01 \pm 0.43$ & & $78 \pm 50$ & \\
\hline $\mathrm{Bz}(1,2,4,5) \mathrm{P}_{4}$ & $1.02 \pm 0.1$ & $\begin{array}{l}69.3 \pm 15.4^{10} \\
108.3 \pm 20.3^{12}\end{array}$ & $4 \pm 2$ & $6.3 \pm 0.8$ \\
\hline
\end{tabular}

better substrates than simple inositol phosphate substrate (Figure 3).

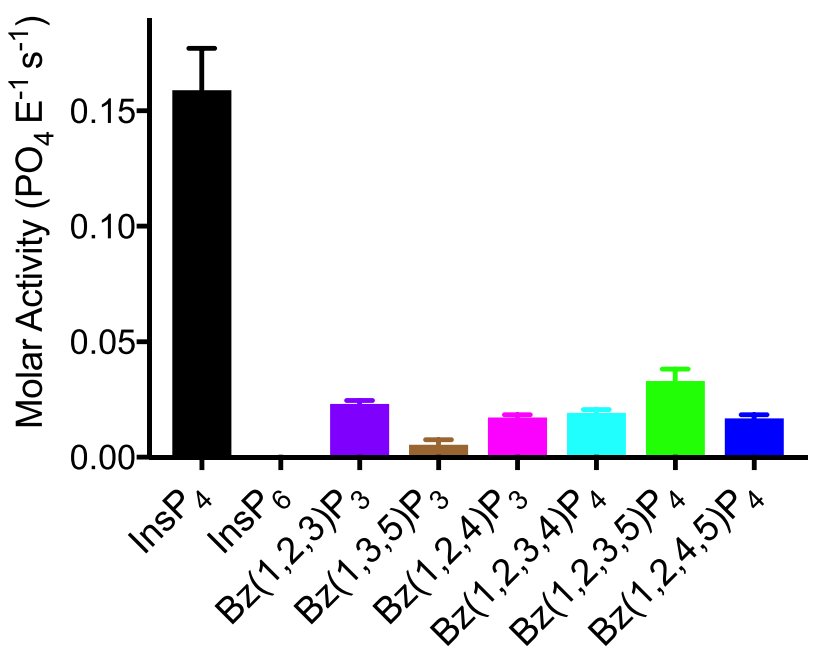

Figure 3. Benzene phosphates as substrates of SHIP2. Compounds tested at $100 \mu \mathrm{M}$. For Ins $(1,3,4,5) \mathrm{P}_{4}$ and $\operatorname{InsP}_{6}$, the concentration of SHIP2 was $1 \mu \mathrm{M}$ and for the benzene phosphates, $4 \mu \mathrm{M}$, with triplicate reactions run for $10 \mathrm{~min}$ at $30{ }^{\circ} \mathrm{C}$.

Ins $(1,3,4,5) \mathrm{P}_{4}$ and $\operatorname{Ins}_{6}$ were included as positive and negative controls, respectively. Phosphate release was determined with molybdenum blue, using ferrous sulfate as a reducing agent. ${ }^{17}$ While slower than the reaction with Ins $(1,3,4,5) \mathrm{P}_{4}$, phosphatase activity was noted with all compounds except InsP $\mathrm{P}_{6}$, a substrate for phytases ${ }^{18}$ but not for inositol polyphosphate 5-phosphatases. As the benzene phosphates are poorer substrates than $\operatorname{Ins}(1,3,4,5) \mathrm{P}_{4}$, the rate of dephosphorylation must be influenced by factors other than just the $\mathrm{pK}_{\mathrm{a}}$ of the leaving group. In an earlier study, ${ }^{11}$ we postulated that $\mathrm{OH}$ groups in the substrate are likely to have a mechanistic role, showing that during dephosphorylation of compound $73-\mathrm{OH}-\mathrm{Bz}(1,2,4) \mathrm{P}_{3}$ by INPP5A, stabilization of the phenolic $\mathrm{OH}$ proton accompanied deprotonation of the phosphate groups. In order to test this theory, we compared phosphate release from compound $73-\mathrm{OH}-\mathrm{Bz}(1,2,4) \mathrm{P}_{3}$ and compound $4 \mathrm{Bz}(1,2,3,4) \mathrm{P}_{4}$ (Figure $\mathrm{S} 1$ ). The rate determined for compound $73-\mathrm{OH}-\mathrm{Bz}(1,2,4) \mathrm{P}_{3}$ was almost twice that observed for compound $4 \mathrm{Bz}(1,2,3,4) \mathrm{P}_{4}$. However, this rate is comparable to that observed for compound $5 \mathrm{Bz}(1,2,3,5) \mathrm{P}_{4}$, suggesting that the regiochemistry of the ring substitution may also have an influence.

Having gained evidence for binding of benzene phosphates to SHIP2 and their catalytic processing by SHIP2, we speculated that the spectroscopic properties of benzene phosphates might be exploited to follow catalysis. Excitation and emission scans of acetonitrile solutions of compound 4 $\mathrm{Bz}(1,2,3,4) \mathrm{P}_{4}$, compound $5 \mathrm{Bz}(1,2,3,5) \mathrm{P}_{4}$, compound $\mathbf{6}$ $\mathrm{Bz}(1,2,4,5) \mathrm{P}_{4}$, and tryptophan were measured, and the spectral details compared to those predicted by TD-DFT (Figure 4 and
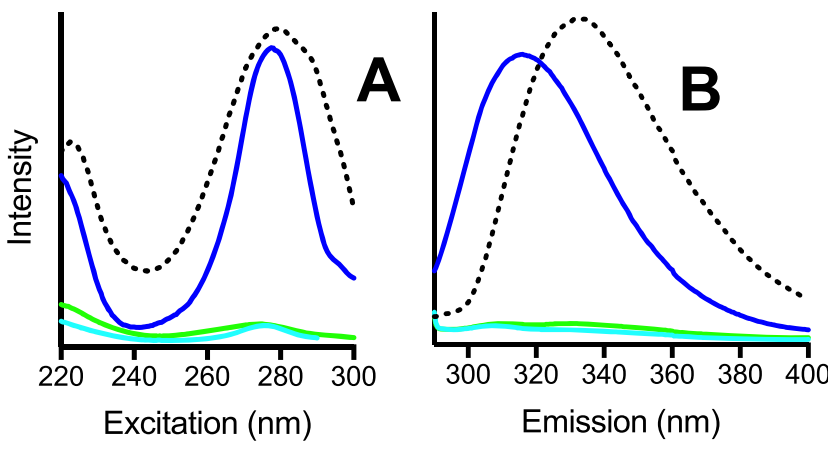

Figure 4. Fluorescence spectra of $500 \mu \mathrm{M} \mathrm{Bz}(1,2,3,4) \mathrm{P}_{4}$ (cyan line), $500 \mu \mathrm{M} \mathrm{Bz}(1,2,3,5) \mathrm{P}_{4}$ (green line), $100 \mu \mathrm{M} \mathrm{Bz}(1,2,4,5) \mathrm{P}_{4}$ (blue line), and $10 \mu \mathrm{M}$ tryptophan (black dotted line) in acetonitrile. (A) Excitation scans determined at emission maxima and (B) emission scans excited at $280 \mathrm{~nm}$.

Tables S1 and S2). Spectral predictions for compound 8 5$\mathrm{OH}-\mathrm{Bz}(1,2,4) \mathrm{P}_{3}$ are included in the table, but the pure compound was not available to test. The theoretical methods employ approaches used in TD-DFT studies of tryptophan. ${ }^{19,20}$ A detailed discussion of the TD-DFT methods and results is included in Supporting Information.

Significantly, on excitation at $280 \mathrm{~nm}$, the measured fluorescence of compound $6 \mathrm{Bz}(1,2,4,5) \mathrm{P}_{4}$ was 30 times more intense than that of the next most fluorescent benzene tetrakisphosphate, compound $5 \mathrm{Bz}(1,2,3,5) \mathrm{P}_{4}$, and approximately $10 \%$ of that of tryptophan (Figure 4). These observations match the trends predicted by TD-DFT (Tables $\mathrm{S} 1$ and S2). The calculations for compound $85-\mathrm{OH}-$ $\mathrm{Bz}(1,2,4) \mathrm{P}_{3}$ predict that the excitation maximum of $5-\mathrm{OH}$ $\mathrm{Bz}(1,2,4) \mathrm{P}_{3}$ is $6 \mathrm{~nm}$ greater than that of compound 6 $\mathrm{Bz}(1,2,4,5) \mathrm{P}_{4}$, a prediction confirmed by empirical measurement (Figure 5 and Table S1). Similarly, TD-DFT predicts the emission maximum for compound $85-\mathrm{OH}-\mathrm{Bz}(1,2,4) \mathrm{P}_{3}$ is 25 $\mathrm{nm}$ greater than that of compound $6 \mathrm{Bz}(1,2,4,5) \mathrm{P}_{4}$ (Figure 5 and Table S2).

As TD-DFT predicts that compound $6 \mathrm{Bz}(1,2,4,5) \mathrm{P}_{4}$ and its hydrolysis product compound 8 5- $\mathrm{OH}-\mathrm{Bz}(1,2,4) \mathrm{P}_{3}$ show significant fluorescence intensity, we devised an HPLC separation that could be used with fluorescence detection for 

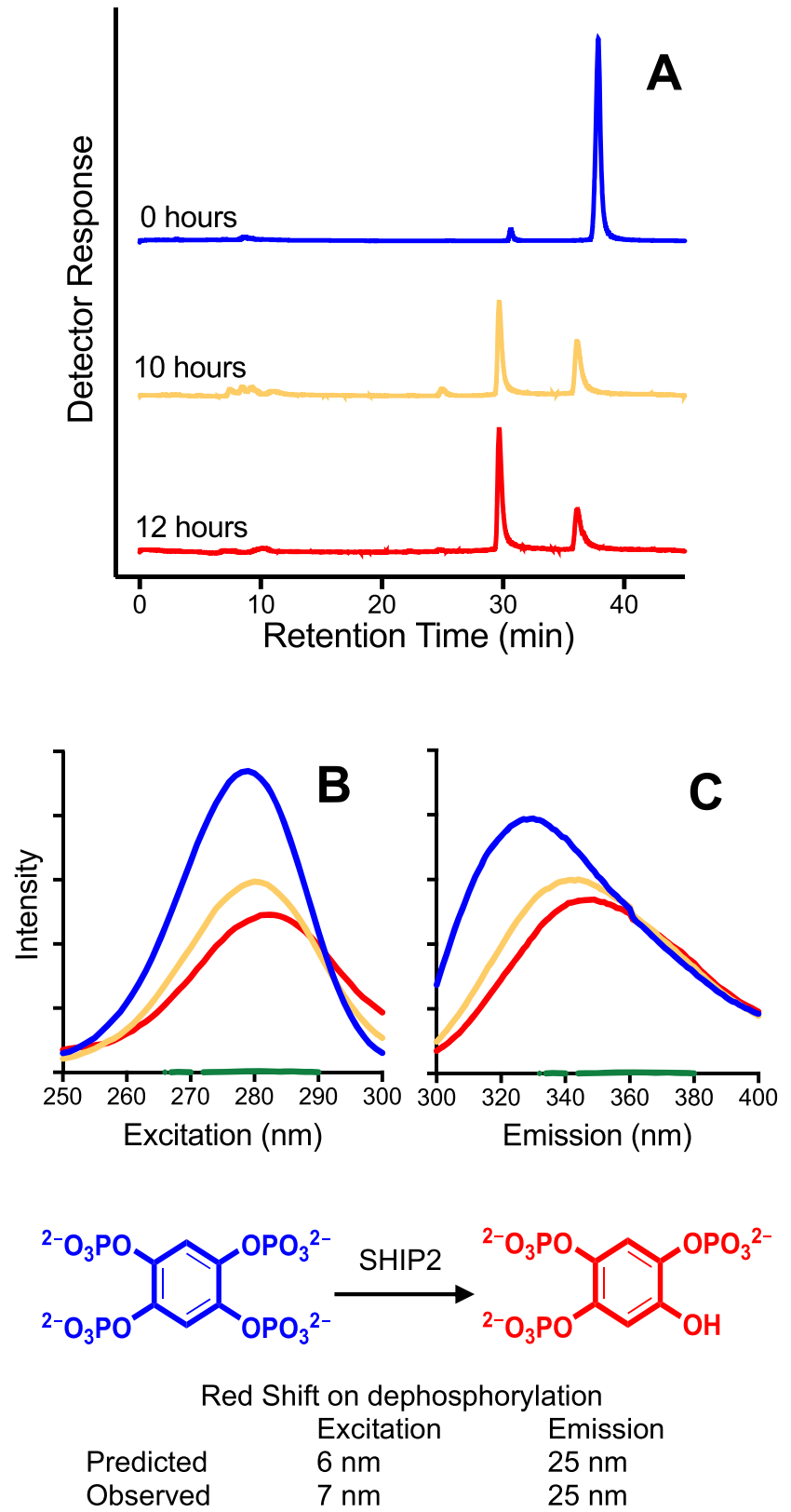

Figure 5. (A) HPLC analysis of reaction of $\mathrm{Bz}(1,2,4,5) \mathrm{P}_{4}(100 \mu \mathrm{M})$ incubated with SHIP2 $(100 \mathrm{nM})$ at $16^{\circ} \mathrm{C}$ for $0 \mathrm{~h}$ (blue line), $10 \mathrm{~h}$ (amber line), and $12 \mathrm{~h}$ (red line). Substrate and products were detected by fluorescence (excitation at $280 \mathrm{~nm}$, emission at $330 \mathrm{~nm}$ ). $(B, C)$ Fluorescence of the same samples diluted 100 -fold in acetonitrile. SHIP2 (100 nM) alone shown as a dark green line on the baseline: (B) excitation scans with emission at $330 \mathrm{~nm}$ and (C) emission scans excited at $280 \mathrm{~nm}$.

benzene phosphates. First, we established separations following UV absorbance (Figure S2). HPLC resolved all the discrete benzene trisphosphates and tetrakisphosphates used in this study. Compound $6 \mathrm{Bz}(1,2,4,5) \mathrm{P}_{4}$ that eluted at approximately 37 min could also be detected by fluorescence with excitation at $280 \mathrm{~nm}$ and emission at $330 \mathrm{~nm}$. In the first instance, we wanted to use the HPLC method to investigate whether SHIP2 could convert compound $6 \mathrm{Bz}(1,2,4,5) \mathrm{P}_{4}$ into compound $85-\mathrm{OH}-\mathrm{Bz}(1,2,4) \mathrm{P}_{3}$. Therefore, we selected conditions that would limit the extent of reaction to a predominant single dephosphorylation. Extended incubation of $100 \mu \mathrm{M}$ of compound $6 \mathrm{Bz}(1,2,4,5) \mathrm{P}_{4}$ with $100 \mathrm{nM}$ SHIP2 allowed us to monitor the progression of the reaction without interference from other fluorescent products as judged by HPLC (Figure 5A). Over a period of $12 \mathrm{~h}$, the fluorescence intensity of the parent peak at $37 \mathrm{~min}$ diminished correlating with the appearance of an earlier-eluting peak at $30 \mathrm{~min}$ (Figure 5A). As we did not have the assumed product, compound $85-\mathrm{OH}-\mathrm{Bz}(1,2,4) \mathrm{P}_{3}$, to confirm the identity of the peak at $30 \mathrm{~min}$ (Figure $5 \mathrm{~A}$ ), we sought confirmation by recording fluorescence excitation and emission spectra of the accumulated products (Figures 5B,C).

Samples analyzed in Figure 5A were diluted 100-fold into acetonitrile, and fluorescence spectra were recorded (Figure $5 \mathrm{~B}, \mathrm{C})$. As the proportion of the product increased, the red shifts in the fluorescence spectra increased correspondingly. After $12 \mathrm{~h}$ incubation, the excitation maximum of the assumed product, compound $85-\mathrm{OH}-\mathrm{Bz}(1,2,4) \mathrm{P}_{3}$, was $7 \mathrm{~nm}$ greater than that of the starting material (Figure 5B). This compares favorably to the shift of $+6 \mathrm{~nm}$ predicted by TD-DFT for compound $6 \mathrm{Bz}(1,2,4,5) \mathrm{P}_{4}$ converting to compound $85-\mathrm{OH}$ $\mathrm{Bz}(1,2,4) \mathrm{P}_{3}$ (Table $\mathrm{S} 1$ ). The emission maximum of the product was $25 \mathrm{~nm}$ greater than that of the starting material (Figure 5C). This also compares favorably to the predicted shift of $+25 \mathrm{~nm}$ for compound $6 \mathrm{Bz}(1,2,4,5) \mathrm{P}_{4}$ converting to compound 8 5-OH-Bz $(1,2,4) \mathrm{P}_{3}$ (Table S2). As discussed in Supporting Information, the predicted transition energies for excitation and emission differ systematically from the experimentally determined values so that variations between compounds can be defined in terms of wavelength shifts. A similar observation has previously been noted for this type of TD-DFT analysis. ${ }^{19,20}$ From the close match between the predicted and observed wavelength shifts, we can conclude that compound $85-\mathrm{OH}-\mathrm{Bz}(1,2,4) \mathrm{P}_{3}$ is formed when compound $6 \mathrm{Bz}(1,2,4,5) \mathrm{P}_{4}$ is incubated with SHIP2 under these conditions.

In order to investigate further the effects of SHIP2 on compound $6 \mathrm{Bz}(1,2,4,5) \mathrm{P}_{4}, 100 \mu \mathrm{M}$ of the substrate was incubated for $2 \mathrm{~h}$ with increasing amounts of SHIP2. This demonstrated that the conversion of compound $6 \mathrm{Bz}(1,2,4,5)$ $\mathrm{P}_{4}$ into its first hydrolysis product, compound $85-\mathrm{OH}$ $\mathrm{Bz}(1,2,4) \mathrm{P}_{3}$, is dependent on the SHIP2 concentration and that compound $6 \mathrm{Bz}(1,2,4,5) \mathrm{P}_{4}$ alone is stable under these conditions (Figure S3). Longer incubation and use of tandem UV-fluorescence detection resulted in a more complicated product profile with peaks of increased absorbance: fluorescence ratio at $30,25,23$, and $13 \mathrm{~min}$ (Figure S4). This is consistent with successive dephosphorylation generating a sequence of different hydroxybenzene phosphate compounds with different elution profiles as observed for inositol phosphates. $^{21}$

The change in fluorescence that accompanies the conversion of substrate to product can be used to develop a real-time fluorescence-based assay to follow dephosphorylation of compound $6 \mathrm{Bz}(1,2,4,5) \mathrm{P}_{4}$ by the exemplar 5-phosphatase SHIP2 (Figure 6). In the absence of competing additives, the fluorescence intensity at $325 \mathrm{~nm}$ reduces, and the maximum shifts to a longer wavelength as the reaction between SHIP2 and compound $6 \mathrm{Bz}(1,2,4,5) \mathrm{P}_{4}$ progresses (Figure 6A). Figure $6 \mathrm{~B}$ traces how the emission intensity at $325 \mathrm{~nm}$ (the maximum for compound $\left.6 \mathrm{Bz}(1,2,4,5) \mathrm{P}_{4}\right)$ decreases with time. It also shows how this decrease is affected by additives that are 

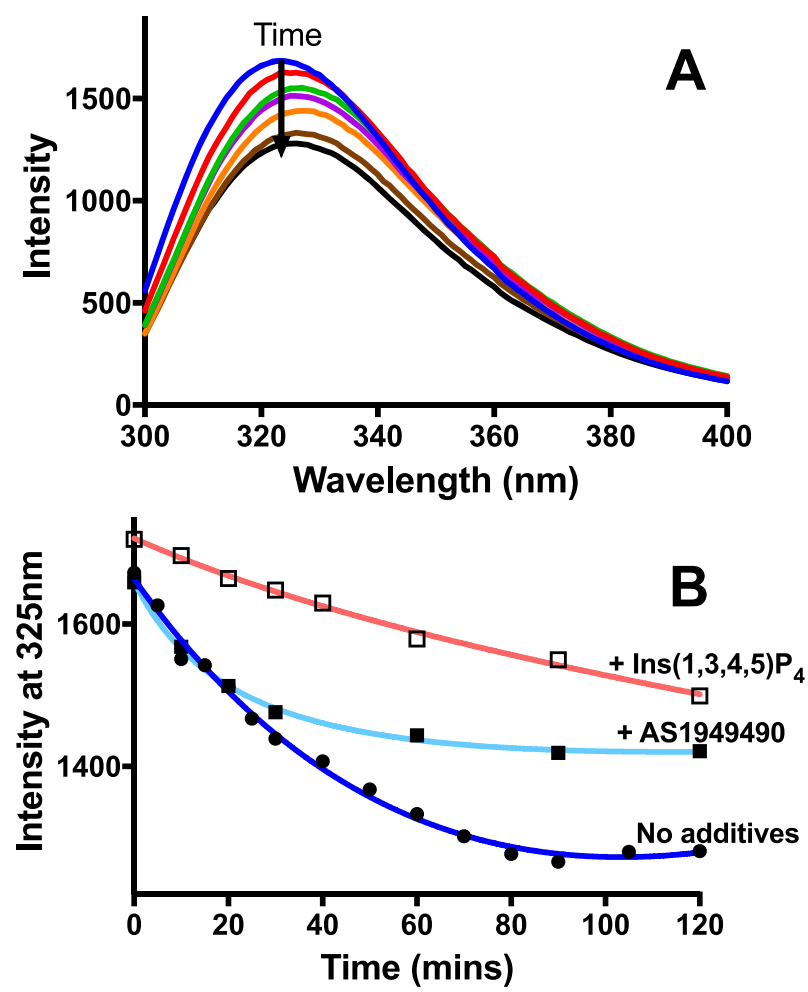

Figure 6. (A) Change in fluorescence of compound $6 \mathrm{Bz}(1,2,4,5) \mathrm{P}_{4}$ $(100 \mu \mathrm{M})$ incubated with SHIP2 $(1 \mu \mathrm{M})$ at $23^{\circ} \mathrm{C}$ recording emission scans excited at $280 \mathrm{~nm}$ over a period of $2 \mathrm{~h}$. (B) Change in emission intensity at $325 \mathrm{~nm}$ with time for compound $6 \mathrm{Bz}(1,2,4,5) \mathrm{P}_{4}$ incubated with SHIP2; with no other additives (dark blue line), with Ins $(1,3,4,5) \mathrm{P}_{4}(50 \mu \mathrm{M})$ (peach line), and with SHIP2 inhibitor AS1949490 (100 $\mu \mathrm{M})$ (light blue line).

reported to be substrates or inhibitors of SHIP2 activity. The rate of the intensity decrease slows down considerably in the presence of the natural substrate $\operatorname{Ins}(1,3,4,5) \mathrm{P}_{4}$, which, as shown in Figure 3, is 10 times more active in terms of phosphate release than any of the benzene phosphates. In the presence of the SHIP2 inhibitor AS1949490, there is an initial decrease in fluorescence intensity that matches that of the reaction with no additives indicating that, in the initial stages under these conditions, we are not seeing inhibition of SHIP2 activity with compound $6 \mathrm{Bz}(1,2,4,5) \mathrm{P}_{4}$. This experiment is not an exhaustive analysis of the substrates competing for SHIP2 activity but serves to demonstrate the utility of benzene phosphate fluorescence in this context.

While there is much to take account of when designing such an experiment, we have proved the utility of TD-DFT to select from a regioisomeric family of benzene tris- and tetrakisphosphates for the compound with the best fluorescent properties to monitor 5-phosphatase, specifically SHIP2, activity. Interestingly, benzene phosphates appear to undergo successive dephosphorylations with SHIP2, in contrast to the single 5-dephosphorylation of inositol phosphate substrates. By judicious choice of a symmetrical tetrakisphosphate and careful titration of enzyme, we were able to limit the extent of reaction to a predominant single dephosphorylation. Interestingly, toward the end of the experiment shown in Figure 6A there is a slight shift to shorter wavelength again, most likely reflecting further dephosphorylation of the 5-OH-Bz $(1,2,4) \mathrm{P}_{3}$ product.

To explore further the catalytic flexibility engendered in phosphate-substituted benzenes, we also sought to define the products of successive dephosphorylation of the more weakly fluorescent compound 4, $\mathrm{Bz}(1,2,3,4) \mathrm{P}_{4}$ (Figure S5), for which a number of potential dephosphorylation products are available. Accordingly, we included compound $73-\mathrm{OH}$ $\mathrm{Bz}(1,2,4) \mathrm{P}_{3}$ and the newly synthesized compounds 9 1,2-Di$\mathrm{OH}-\mathrm{Bz}(3,4) \mathrm{P}_{2}$ and 10 1,3-Di-OH-Bz $(2,4) \mathrm{P}_{2}$ in our analysis (full details and structures of these compounds are given in Supporting Information). We did not detect the accumulation of compound $7,3-\mathrm{OH}-\mathrm{Bz}(1,2,4) \mathrm{P}_{3}$ from compound 4 $\mathrm{Bz}(1,2,3,4) \mathrm{P}_{4}$. This does not rule out its production or that of $1-\mathrm{OH}-\mathrm{Bz}(2,3,4) \mathrm{P}_{3}$ as there is the possibility that the first product of hydrolysis is rapidly dephosphorylated to $\mathrm{Di}-\mathrm{OH}$ $\mathrm{BzP}_{2}$ products. Indeed, compound 9 1,2-Di-OH-Bz $(3,4) \mathrm{P}_{2}=$ 3,4-Di-OH-Bz $(1,2) \mathrm{P}_{2}$ was generated by SHIP2 from compound $4 \mathrm{Bz}(1,2,3,4) \mathrm{P}_{4}$ (Figure $\mathrm{S} 4$ ) and, from Figure $\mathrm{S} 1$, we can see that compound $73-\mathrm{OH}-\mathrm{Bz}(1,2,4) \mathrm{P}_{3}$ is a better phosphate-releasing substrate than compound $4 \mathrm{Bz}(1,2,3,4) \mathrm{P}_{4}$. Consistently, SHIP2 action on compound $73-\mathrm{OH}-\mathrm{Bz}(1,2,4) \mathrm{P}_{3}$ yielded multiple products including compound 9 1,2-Di-OH$\mathrm{Bz}(3,4) \mathrm{P}_{2}=3,4-\mathrm{Di}-\mathrm{OH}-\mathrm{Bz}(1,2) \mathrm{P}_{2}$, but not compound $101,3-$ Di-OH-Bz $(2,4) \mathrm{P}_{2}=2,4-\mathrm{Di}-\mathrm{OH}-\mathrm{Bz}(1,3) \mathrm{P}_{2}$ (Figure S4). [2,3Di-OH-Bz $(1,4) \mathrm{P}_{2}$ was not available to test.] The intricacies of this analysis demonstrate further the advantages of a planned approach to selecting substrates with the most suitable properties for probing selected mechanisms of protein activity.

To summarize, with interest in the utility of benzene phosphates as ligands of diverse inositide/phosphoinositidebinding proteins/enzymes, we have shown that, uniquely among characterized ligands of 5-phosphatases, benzene phosphates have the properties of bona fide substrate analogs. Indeed, benzene tris- and tetrakisphosphates are inhibitors of Type I and Type II inositol polyphosphate 5-phosphatases, 9,12 while compound $4 \mathrm{Bz}(1,2,3,4) \mathrm{P}_{4}$ is a tight binding ligand of the $\mathrm{PH}$ domain of $\mathrm{PKB} /$ Akt. $^{22}$ Compound $6 \mathrm{Bz}(1,2,4,5) \mathrm{P}_{4}$ is an inhibitor of SHIP $2^{10}$ and a structure was solved for a binary complex with INPP5B. ${ }^{12}$ Here we show that benzene phosphates are surrogate substrates of the canonical 5phosphatase SHIP2 by virtue of their regiochemistry. This mimics well the stereoisomerism but not enantiomerism of inositides and phosphoinositides. Clearly these compounds could find utility with a range of inositol phosphate phosphatases beyond 5-phosphatases, e.g., 3-phosphatases typified by PTEN or 4-phosphatases such as SopB. The demonstration that they are substrates and can be used for real-time assays affords great opportunity for the study of allosteric regulation of catalytic activity by ligand binding to distal domains of the full-length protein.

Because of its relatively strong absorption and fluorescence emission, compound $6 \mathrm{Bz}(1,2,4,5) \mathrm{P}_{4}$ is shown to be a promising spectroscopic probe for inositol 5-phosphatase(s). It may also be of use for proteins lacking catalytic activity since, as demonstrated, it is a good ligand of inositol phosphatebinding sites. Beyond this, the combination of TD-DFT and enzymological approaches could direct the synthesis of new probes for the study of specific aspects of protein structure and function. For real time assays, designed to screen potential inhibitors of protein activity, there is opportunity to design chromophores with enhanced, perhaps further red-shifted, fluorescence. Spectral separation from tryptophan, either in 
excitation and/or emission, might enable polarization-based approaches to inhibitor screening of inositol phosphatemetabolizing enzymes as we have described with 2-FAMIns $_{5}$ for IPK $1,{ }^{13}$ but without the potential constraints of bulky fluorophore substituents. Probes might be synthesized to retain the ligand coordination of bona fide substrates and/or might afford a range of binding constants tailored for particular experimental scenarios, cf. ion-sensing fluorescent probes. Thus, we envisage our methods will enable prediction and testing of poly-substituted benzenes that retain the regiochemistry of a favored ligand while building in the spectroscopic opportunity of substitution with other functionalities. The diversification of simple aryl ligands to include other functionalities may further find use as structure-stabilizing ligands enabling crystallization of recalcitrant inositol-related protein targets. ${ }^{12}$ In summary, there is wide-ranging potential in this field for the application of TD-DFT to aid decisions over probe synthesis and experiment design.

\section{ASSOCIATED CONTENT}

\section{S Supporting Information}

The Supporting Information is available free of charge on the ACS Publications website at DOI: 10.1021/acsmedchemlett.9b00368.

Experimental Procedures including chemical syntheses, protein purification, analytical methods, and TD-DFT calculations. Figure S1: Assay of benzene phosphates and hydroxybenzene phosphates as substrates of SHIP2. Figure S2: HPLC separation of benzene phosphates. Figure S3: HPLC of SHIP2 action on compound 6 $\mathrm{Bz}(1,2,4,5) \mathrm{P}_{4}$, Figure S4: Tandem UV-fluorescence HPLC assay of SHIP2 action on compound 6 $\mathrm{Bz}(1,2,4,5) \mathrm{P}_{4}$. Figure S5: HPLC separation of compound $4 \mathrm{Bz}(1,2,3,4) \mathrm{P}_{4}$, compound $73-\mathrm{OH}-\mathrm{Bz}(1,2,3) \mathrm{P}_{3}$, compound 9 1,2-Di-OH-Bz $(3,4) \mathrm{P}_{2}$, and compound 10 1,3-Di-OH-Bz(2,4) $\mathrm{P}_{2}$. TD-DFT: Results, Tables, and Figures (PDF)

\section{AUTHOR INFORMATION}

\section{Corresponding Authors}

*Tel: +44 1603 592197. E-mail: c.brearley@uea.ac.uk.

*Tel: +44 1865 271945. E-mail: barry.potter@pharm.ox.ac.uk. *Tel: +44 1603 592698. E-mail: v.oganesyan@uea.ac.uk.

\section{ORCID}

Andrew M. Riley: 0000-0001-9003-3540

Barry V. L. Potter: 0000-0003-3255-9135

Charles A. Brearley: 0000-0001-6179-9109

\section{Author Contributions}

"These authors contributed equally to this work. G.W., K.B., H.W., C.P., S.J.M. and C.A.B. performed experiments. G.W., V.O., S.J.M., A.M.R., B.V.L.P., and C.A.B. designed the study and wrote the manuscript.

\section{Funding}

Funding that enabled this study was obtained by C.A.B. (BBSRC BB/N002024/1 with contribution from AB Vista), V.S.O. (EPSRC EP/P007554/1), and B.V.L.P. (Wellcome Trust Senior Investigator Grant 101010). K.B. acknowledges support from $\mathrm{AB}$ Vista.

\section{Notes}

The authors declare no competing financial interest.

\section{ABBREVIATIONS}

2-FAM-InsP $\mathrm{P}_{5}, \quad 2-\mathrm{O}$-(2-(5-fluoresceinylcarboxy)-aminoethyl)myo-inositol 1,3,4,5,6-pentakisphosphate (triethylammonium salt); 3-OH-Bz(1,2,4) $\mathrm{P}_{3}$, 3-hydroxybenzene 1,2,4-trisphosphate; 5-OH-Bz $(1,2,4) \mathrm{P}_{3}$, 5-hydroxybenzene 1,2,4-trisphosphate; 1,2-Di-OH-Bz $(3,4) \mathrm{P}_{2}, \quad 1,2$-dihydroxybenzene-3,4-bisphosphate; 1,3-Di-OH-Bz $(2,4) \mathrm{P}_{2}$, 1,3-dihydroxybenzene-2,4bisphosphate; 2,3-Di-OH-Bz $(1,4) \mathrm{P}_{2}$, 2,3-dihydroxybenzene1,4-bisphosphate; $\mathrm{BzP}$, benzene phosphate; $\mathrm{Bz}(1,2,3) \mathrm{P}_{3}$, benzene 1,2,3-trisphosphate; $\mathrm{Bz}(1,2,4) \mathrm{P}_{3}$, benzene 1,2,4-trisphosphate; $\mathrm{Bz}(1,3,5) \mathrm{P}_{3}$, benzene 1,3,5-trisphosphate; $\mathrm{Bz}$ $(1,2,3,4) \mathrm{P}_{4}$, benzene 1,2,3,4-tetrakisphosphate; $\mathrm{Bz}(1,2,3,5) \mathrm{P}_{4}$, benzene 1,2,3,5-tetrakisphosphate; $\mathrm{Bz}(1,2,4,5) \mathrm{P}_{4}$, benzene 1,2,4,5-tetrakisphosphate; EDTA, ethylenediamine tetra-acetic acid; HEPES, 4-(2-hydroxyethyl)-1-piperazineethane sulfonic acid; His, histidine; HOMO, highest occupied molecular orbital; HPLC, high-pressure liquid chromatography; $\mathrm{IC}_{50}$, half-maximal inhibitory concentration; INPP5A, type I inositol 5-phosphatase; INPP5B, type II inositol 5-phosphatase; INPP5E, inositol polyphosphate 5-phosphatase E; Ins $(1,4,5)$ $\mathrm{P}_{3}$, inositol 1,4,5-trisphosphate; Ins $(1,3,4,5) \mathrm{P}_{4}$, inositol $1,3,4,5$ tetrakisphosphate; LUMO, lowest unoccupied molecular orbital; OCRL-1, Lowe oculocerebrorenal syndrome protein (INPP5F); PKB, Protein Kinase B; PtdIns $(3,4) \mathrm{P}_{2}$, phosphatidylinositol 3,4-bisphosphate; PtdIns $(4,5) \mathrm{P}_{2}$, phosphatidylinositol 4,5-bisphosphate; PtdIns $(3,4,5) \mathrm{P}_{3}$, phosphatidylinositol 3,4,5-trisphosphate; SYNJ1, synaptojanin-1; SYNJ2, synaptojanin-2; SHIP1, SH2-domain containing inositol 5-phosphatase type 1; SHIP2, SH2-domain containing inositol 5phosphatase type 2; TCEP, tris(2-carboxyethyl) phosphine; TD-DFT, time-domain density functional theory; TEV, Tobacco Etch Virus

\section{REFERENCES}

(1) Abel, K.; Anderson, R. A.; Shears, S. B. Phosphatidylinositol and inositol phosphate metabolism. J. Cell. Sci. 2001, 114 (Pt 12), 22078.

(2) Ooms, L. M.; Horan, K. A.; Rahman, P.; Seaton, G.; Gurung, R.; Kethesparan, D. S.; Mitchell, C. A. The role of the inositol polyphosphate 5-phosphatases in cellular function and human disease. Biochem. J. 2009, 419 (1), 29-49.

(3) Zhang, J.; Liu, Z.; Rasschaert, J.; Blero, D.; Deneubourg, L.; Schurmans, S.; Erneux, C.; Pesesse, X. SHIP2 controls PtdIns $(3,4,5)-$ $\mathrm{P}(3)$ levels and $\mathrm{PKB}$ activity in response to oxidative stress. Cell. Signalling 2007, 19 (10), 2194-200.

(4) Le Coq, J.; Camacho-Artacho, M.; Velazquez, J. V.; Santiveri, C. M.; Gallego, L. H.; Campos-Olivas, R.; Dolker, N.; Lietha, D. Structural basis for interdomain communication in SHIP2 providing high phosphatase activity. eLife 2017, 6, e26640.

(5) Thomas, M. P.; Erneux, C.; Potter, B. V. L. SHIP2: Structure, Function and Inhibition. ChemBioChem 2017, 18 (3), 233-247.

(6) Dalton, S. E.; Dittus, L.; Thomas, D. A.; Convery, M. A.; Nunes, J.; Bush, J. T.; Evans, J. P.; Werner, T.; Bantscheff, M.; Murphy, J. A.; Campos, S. Selectively Targeting the Kinome-Conserved Lysine of PI3Kdelta as a General Approach to Covalent Kinase Inhibition. J. Am. Chem. Soc. 2018, 140 (3), 932-939.

(7) Miller, M. S.; Thompson, P. E.; Gabelli, S. B. Structural Determinants of Isoform Selectivity in PI3K Inhibitors. Biomolecules 2019, 9 (3), 82.

(8) Suwa, A.; Yamamoto, T.; Sawada, A.; Minoura, K.; Hosogai, N.; Tahara, A.; Kurama, T.; Shimokawa, T.; Aramori, I. Discovery and functional characterization of a novel small molecule inhibitor of the intracellular phosphatase, SHIP2. Br. J. Pharmacol. 2009, 158 (3), 879-887. 
(9) Mills, S. J.; Vandeput, F.; Trusselle, M. N.; Safrany, S. T.; Erneux, C.; Potter, B. V. L. Benzene polyphosphates as tools for cell signalling: inhibition of inositol 1,4,5-trisphosphate 5-phosphatase and interaction with the $\mathrm{PH}$ domain of protein kinase $\mathrm{B} \alpha$. ChemBioChem 2008, 9 (11), 1757-66.

(10) Mills, S. J.; Persson, C.; Cozier, G.; Thomas, M. P.; Tresaugues, L.; Erneux, C.; Riley, A. M.; Nordlund, P.; Potter, B. V. L. A synthetic polyphosphoinositide headgroup surrogate in complex with SHIP2 provides a rationale for drug discovery. ACS Chem. Biol. 2012, 7 (5), $822-8$.

(11) Mills, S. J.; Dozol, H.; Vandeput, F.; Backers, K.; Woodman, T.; Erneux, C.; Spiess, B.; Potter, B. V. L. 3-hydroxybenzene 1,2,4trisphosphate, a novel second messenger mimic and unusual substrate for type-I myo-inositol 1,4,5-trisphosphate 5-phosphatase: Synthesis and physicochemistry. ChemBioChem 2006, 7 (11), 1696-706.

(12) Mills, S. J.; Silvander, C.; Cozier, G.; Tresaugues, L.; Nordlund, P.; Potter, B. V. L. Crystal Structures of Type-II Inositol Polyphosphate 5-Phosphatase INPP5B with Synthetic Inositol Polyphosphate Surrogates Reveal New Mechanistic Insights for the Inositol 5-Phosphatase Family. Biochemistry 2016, 55 (9), 13841397.

(13) Whitfield, H.; Gilmartin, M.; Baker, K.; Riley, A. M.; Godage, H. Y.; Potter, B. V. L.; Hemmings, A. M.; Brearley, C. A. A Fluorescent Probe Identifies Active Site Ligands of Inositol Pentakisphosphate 2-Kinase. J. Med. Chem. 2018, 61 (19), 8838-8846.

(14) Riley, A. M.; Windhorst, S.; Lin, H. Y.; Potter, B. V. L. Cellular internalisation of an inositol phosphate visualised by using fluorescent InsP $\mathrm{P}_{5}$. ChemBioChem 2014, 15 (1), 57-67.

(15) Kirby, A. J.; Nome, F. Fundamentals of phosphate transfer. Acc. Chem. Res. 2015, 48 (7), 1806-14.

(16) Pabis, A.; Duarte, F.; Kamerlin, S. C. Promiscuity in the Enzymatic Catalysis of Phosphate and Sulfate Transfer. Biochemistry 2016, 55 (22), 3061-81.

(17) Taussky, H. H.; Shorr, E. A Microcolorimetric Method for the Determination of Inorganic Phosphorus. J. Biol. Chem. 1953, 202 (2), 675-685.

(18) Gruninger, R. J.; Dobing, S.; Smith, A. D.; Bruder, L. M.; Selinger, L. B.; Wieden, H. J.; Mosimann, S. C. Substrate binding in protein-tyrosine phosphatase-like inositol polyphosphatases. J. Biol. Chem. 2012, 287 (13), 9722-30.

(19) Caricato, M.; Mennucci, B.; Tomasi, J.; Ingrosso, F.; Cammi, R.; Corni, S.; Scalmani, G. Formation and relaxation of excited states in solution: a new time dependent polarizable continuum model based on time dependent density functional theory. J. Chem. Phys. 2006, 124 (12), 124520-1.

(20) Al-Soliemy, A. M.; Osman, O. I.; Hussein, M. A.; Asiri, A. M.; El-Daly, S. A. Fluorescence, Photophysical Behaviour and DFT Investigation of E,E-2,5-bis[2-(3-pyridyl)ethenyl]pyrazine (BPEP). J. Fluoresc. 2016, 26 (4), 1199-209.

(21) Kuo, H. F.; Hsu, Y. Y.; Lin, W. C.; Chen, K. Y.; Munnik, T.; Brearley, C. A.; Chiou, T. J. Arabidopsis inositol phosphate kinases, IPK1 and ITPK1, constitute a metabolic pathway in maintaining phosphate homeostasis. Plant J. 2018, 95, 613.

(22) Mills, S. J.; Komander, D.; Trusselle, M. N.; Safrany, S. T.; van Aalten, D. M.; Potter, B. V. L. Novel inositol phospholipid headgroup surrogate crystallized in the pleckstrin homology domain of protein kinase Balpha. ACS Chem. Biol. 2007, 2 (4), 242-6. 